\title{
Notas sobre práticas de jardinagem, relações mercadológicas e seus efeitos na produção e reprodução da "cultura canábica"
}

\author{
Yuri José De Paula Motta ${ }^{1}$ \\ Marcos Veríssimo²
}

Resumo

A presente proposta se estrutura a partir da interlocução, já construída pelos autores, com pessoas que, no Rio de Janeiro, se dedicam, por diferentes motivos, a práticas de jardinagem visando colher maconha (Cannabis sativa L.). Muitos destes cultivadores são também pessoas que militam por formas menos proibicionistas de regular a produção, circulação, mercados e consumos dessa planta. Para estes, plantar para consumo próprio, procurando não capitalizar as redes criminosas que controlam a venda no varejo deste produto através das chamadas "bocas de fumo", são palavras de ordem postas em prática. Por isso quase que totalmente se mostraram refratários a práticas de mercado envolvendo seus cultivos, embora este possa se configurar um negócio bastante lucrativo na cidade do Rio de Janeiro. Neste trabalho que agora propomos, pretendemos, por outro lado, focar em processos de cultivos domésticos dedicados à venda do produto em mercados clandestinos. A metodologia empregada será a leitura de processos nos quais pessoas já incriminadas na justiça por tais práticas figuram como réus, e também material produzido a partir de entrevistas com advogados e ativistas antiproibicionistas.

Palavras-chave: maconha; mercados; cultivos caseiros; inquéritos policiais.

Notes about gardening practices, market relations and their effects on the production and reproduction of "cannabis culture"

Abstract

The present proposal is based on the dialogue already built by the authors with people who, in Rio de Janeiro, dedicate themselves, for different reasons, to gardening practices aimed to harvest marijuana (Cannabis sativa L.). Many of these cultivators are also people who militate for less prohibitive ways of regulating the production, circulation, markets and consumption of this plant. For them, planting for their own consumption, trying not to capitalize on the criminal networks that control the retail sale of this product through the so-called "mouths", are words of orders put into practice. This is why they were almost totally refractory to market practices involving their cultivation, although this may be a very lucrative business in the city of Rio de Janeiro. In this work we are now proposing, on the other hand, we intend to focus on domestic cultivation processes dedicated to selling the product in clandestine markets. The methodology employed will be the reading of cases in which people already accused in court for such practices appear as defendants, as well as material produced from interviews with lawyers and anti-prohibition activists.

1 Doutorando pelo Programa de Pós-Graduação em Sociologia e Direito da Universidade Federal Fluminense (PPGSD/ UFF).

2 Doutor em Antropologia pelo Programa de Pós-Graduação em Antropologia da Universidade Federal Fluminense (UUF) e Professor de sociologia da Secretaria Estadual de Educação do Rio de Janeiro. 
Keywords: Transcendental realism; critical naturalism; philosophy of the natural sciences; philosophy of the social sciences; stratified ontology

\section{Introdução}

Este trabalho tem como objetivo analisar, dentro das limitações impostas pelo campo, a prática de cultivo caseiro de maconha para fins comerciais na cidade do Rio de Janeiro. Conduta tida como crime de acordo com o artigo 33, inciso II, da Lei 11.343 de 2006, podendo quem a isto se dedica ser enquadrado na lei como traficante de drogas. Em trabalhos anteriores (VERISSIMO: 2017; MOTTA: 2020), tivemos a oportunidade de descrever em parte os contextos de sociabilidade da chamada "cultura canábica" com foco nos cultivos domésticos para fins "sociais" e "terapêuticos", respectivamente ${ }^{3}$. Desse modo, até então tínhamos tomado como interlocutores apenas pessoas que, apesar de correrem o risco de plantar maconha podendo ser incriminados como traficantes, através de seus discursos e condutas tornadas públicas, rejeitavam veementemente a venda daquilo que resultava da dedicação de seu tempo e seus afetos. Demonstravam, inclusive, relativo repúdio à mercantilização dos produtos obtidos a partir de suas práticas refinadas de jardinagem.

"Não compre, plante", já dizia o título da canção lançada em 1995 pela lendária banda Planet Hemp, no álbum Usuário. Para além de sua apropriação no cancioneiro popular, esta frase ilustra valores cultivados por aqueles que, no Rio de Janeiro no início da corrente década (2010-2013), plantavam maconha e realizavam ativismo antiproibicionista (VERISSIMO, 2017). Autossuficiência era uma palavra de ordem. Havia troca de excedentes, mas nunca visando o lucro monetário, e sim uma economia baseada na dádiva e no prestígio (MAUSS, 2003). Os cultivadores domésticos (growers) se reuniam em encontros sociais como aniversários, além de atos de ativismo, e experimentavam de maneira compartilhada o produto de suas colheitas, elaborando assim sistemas classificatórios que contribuíram para a produção de um conhecimento refinado sobre as variedades da Cannabis sativa L., que é o nome científico da planta conhecida no Brasil como maconha.

O cientista social Sergio Vidal, em seu pioneiro trabalho sobre cultivos domésticos de maconha e "cultura canábica" no Brasil, intitulado "Colhendo Kilobytes:o Growroom e a cultura do cultivo de maconha no Brasil", já chama atenção para este posicionamento político e pragmático adotado por estes cultivadores e ativistas.

(...) De 2001 para cá, alguns membros da comunidade foram presos e acusados de tráfico de drogas e, em geral, foram submetidos a longos períodos de encarceramento antes de conseguirem ser reconhecidos como usuários. Esses episódios causaram grande comoção na comunidade $\mathrm{e}$ o crescimento do interesse de que a figura do cultivador passasse a ser reconhecida social e legalmente (VIDAL, 2010, p. 13).

Posteriormente, novos e decisivos fatores foram introduzidos nesta discussão. Entre os anos de 2014 e 2015, por conta da pressão popular, o Estado brasileiro iniciou o processo de regulação da importação do óleo de maconha para fins terapêuticos. Nesse caso, tratando-se em grande parte de doenças como epilepsia refratária em crianças, grupos de mães requisitaram na justiça o direito de cuidarem de seus filhos e filhas com um produto até então proibido no país, sendo necessária, portanto, a importação, muitas vezes ilegal. Devido à lentidão burocrática e ao alto custo do tratamento, muitas famílias lançaram mão do cultivo doméstico para produzirem artesanalmente o óleo, contando com o apoio de associações canábicas que fornecem auxílio médico e jurídico e também suporte técnico

3 As formas de denominar os usos aqui adotadas - "sociais", "terapêuticos" - tratam-se de categorias nativas. A primeira faz referência a usos comumente denominados como "recreativos", denominação criticada por parte de nossos interlocutores por supostamente infantilizar suas ações. A segunda tem como base a apropriação dos efeitos clínicos do consumo da planta em diferentes terapias. 
de cultivo através de visitas à domicilio e on-line. Essas associações são formadas por advogados, médicos, pesquisadores, ativistas, growers, pacientes e seus familiares com o intuito de se apropriarem sistematicamente dos conhecimentos gerados no meio grower sobre as propriedades da planta, ensejando também a autossuficiência na produção artesanal do óleo para tratamento (MOTTA, 2020).

Não obstante o nosso foco em modalidades de produção e consumo de maconha não direcionadas à venda, não nos escapou a existência de growers que destinam parte de sua produção para fins comerciais. Sendo assim, esta constatação nos despertou o interesse em descrever e interpretar a modalidade de cultivo mercadológica, com seus produtores, mercadores e consumidores, como parte da assim denominada "cultura canábica". Cultivar maconha não é uma tarefa propriamente simples, exigindo, inclusive, da pessoa que a isto se dedica, boa parte do seu tempo, atenção, e em alguns casos, investimento em dinheiro. Se assim o é para obtenção de autossuficiência visando o consumo próprio, no caso de produção para pôr o produto em mercados clandestinos que pressupõem a produção de excedentes em maior quantidade, este cuidado e dedicação pode, não raro, assumir o status de atividade laboral.

Desse modo, em nossas pesquisas anteriores, nunca tivemos acesso a cultivadores que colocavam a venda seus produtos, relativamente valorizados, sobretudo quando comparados ao prensado de origem paraguaia amplamente presente nos mercados clandestinos através do nome de maconha. Afinal, faz parte de certo profissionalismo, neste caso, se resguardar para (com razão) evitar que sejam incriminados e enquadrados no artigo $33 \mathrm{da}$ Lei de Drogas (tráfico). Portanto, está longe de fazer parte de seus planos estabelecer conversas com pesquisadores como os autores do presente trabalho - não raro, erroneamente confundidos com jornalistas e investigadores policiais.

Com o intuito de superar esta ordem de dificuldades de acesso ao campo e a seus operadores nativos, que nos permitiria realizar uma etnografia do contexto grower comercial, recorremos aos nossos interlocutores que realizam ativismo antiproibicionista por via do direito. Advogados que realizam o trabalho de defender na Justiça aqueles que, por conta de seus atos de jardinagem, são obrigados a dar explicações formais em Inquéritos Policiais para não serem presos como traficantes. Por meio de nossos interlocutores, e com permissão dos envolvidos que não quiseram falar diretamente conosco, tivemos acessos a Inquéritos Policiais que continham investigações eacusações contra os mesmos. Desse modo, o presente trabalho é sobre pessoas que tiveram problemas com a justiça, e a descrição que faremos dos acontecimentos foram extraídas de documentos oficiais do Judiciário complementados com conversas que tivemos junto a nossos interlocutores, os advogados.

\section{Relações: entrando nos radares investigativos}

Careca era um grower ativo e reconhecido por grande parte daqueles que, como ele, no Rio de Janeiro da primeira década deste século, se dedicavam à produção caseira de maconha. Sua presença virtual era marcante no site Growroom: seu espaço para crescer ${ }^{4}$, chegando a ter sido um top post, ou seja, durante determinado período de tempo foi o dono do perfil com mais interações, publicações realizadas e visualizadas. Ao contrário do que ditava o pensamento dominante entre seus pares, Careca pensava que a discussão sobre regulação da maconha no Brasil necessariamente deveria levar em conta o estabelecimento de um mercado legal, incluindo o reconhecimento da jardinagem canábica como uma atividade profissional com direitos reconhecidos e remuneração condigna. Por conta de tais posicionamentos, embora muito

4 Consiste o Growroom em um espaço cibernético onde, desde o ano de 2002, cultivadores caseiros de maconha socializavam entre si através de fóruns e chats para trocarem experiências e saberes sobre esta prática. Além disso, serviu de plataforma para a produção de ativismos não apenas no espaço virtual, a exemplo das marchas da maconha em diversas cidades do país (VIDAL, 2010). 
ativo nas redes sociais, participava pouco de encontros presenciais (festas, atos de ativismo etc.) que à época começavam a se intensificar entre os membros do Growroom, propiciando ao etnógrafo a ambiência para seu trabalho de campo (VERISSIMO, 2017).

Além disso, Careca é portador de patologia neurológica causadora de um quadro epilético. Portanto, a definição de sua identidade no campo é complexa: cultivador caseiro, consumidor para fins sociais, mas também terapêuticos, e, há muito tempo, postulante à legitimação dos fins lucrativos da atividade grower. Segundo nos relataram os advogados, em um determinado momento, Careca, que por conta de sua doença tem dificuldades sérias para se manter no mercado de trabalho formal, decidiu vender parte de seu excedente como cultivador de sucesso no mercado clandestino, obtendo assim manutenção financeira. E assim se manteve por um tempo. Segundo nossos interlocutores, esta atividade jamais propiciou grande margem de lucro a Careca. Havia demanda, ou seja, um considerável número de pessoas dispostas a pagar relativamente mais caro por maconha proveniente de uma jardinagem atenta e afetiva efetuada pelos cultivadores caseiros do que pelo prensado que predomina nos mercados clandestinos cariocas. Mas nem por isso, afirmam, Careca demonstrou disposição de praticar preços demasiadamente valorados.

Por diversas vezes vendeu o produto para seus pares (outros growers) a preços "camaradas", ou seja, relativamente baixos em relação aos valores praticados por outros agentes que punham seus produtos neste mercado, onde, não raro, o luxo de apreciar um cigarro proveniente de cultivos caseiros de maconha não costuma ser barato. Como pesquisas anteriores demonstraram (VIDAL, 2010; VERISSIMO, 2017; MOTTA, 2020) a jardinagem canábica, como todas as artes e todas técnicas humanas, contem o elemento da imprevisibilidade, que faz com que uma rede de relações possa ser acionada caso intempéries (ambientais, técnicas, tecnológicas ou policiais) aconteçam, tendo assim sua subsistência ameaçada (VERISSIMO, 2016). O “preço camarada" ao qual nos referimos, faz parte deste tipo de trocas, onde o prestígio enquanto grower, notadamente no que se refere ao comprador, é uma variante decisiva no estabelecimento dos preços neste mercado específico.

"De grower para grower": esta expressão nos fora apresentada por nossos interlocutores, os advogados. E exprime o princípio de lealdade estabelecido através de laços de confiança, compartilhados por meio de etiquetas e valores associados à "cultura canábica”. É isso que faz com que haja este preço relativamente mais baixo quando quem compra é também um cultivador reconhecido por esta rede. Careca teria feito isso diversas vezes. Transar o excedente de cultivos tratados com amor e dedicação durante meses não é, necessariamente, uma operação que envolva unicamente motivações utilitárias (STUART MILL, 2007) em torno de ganhos monetários. Por isso, Careca era relativamente reconhecido neste seleto mercado de grower para grower, por salvar os amigos que, por um motivo ou outro, tiveram problemas no cultivo que os impossibilitou de colher.

Como demonstrado por Carolina Grillo, em "Fazendo doze na pista: um estudo de caso do mercado ilegal de drogas na classe média", o tráfico realizado por jovens de classe média do Rio de Janeiro, também prima pela confiança e pessoalidade como fiadores das relações, a princípio mercantis. Por isso, diferentemente do que ocorre no âmbito do trafico de drogas praticado nas favelas por meio das bocas de fumo, a violência não figurava como uma linguagem no seio destas relações. Em alguma medida, jovens de classe média da cidade do Rio de Janeiro também formam um grupo de pares, sendo que aquilo que Sergio Vidal chama de comunidade grower é um grupo de pares mais restrito ainda no universo dos jovens da classe média. No caso dos interlocutores com os quais estabelecemos relações no campo, predominam os jovens de classe média e profissionais liberais, mas há aparentemente membros de variados estratos sociais.

Certa manhã do ano de 2015, Careca foi surpreendido por policiais que chegaram à 
sua residência portando mandados de busca e apreensão e acusando-o de fazer parte de uma rede criminosa dedicada ao tráfico de drogas. Cães farejadores fizeram parte da operação policial. Como consequência, apreenderam, além de todo seu material de cultivo (incluindo lâmpadas, fertilizantes e sementes), ele próprio, computadores etc... O produto desta ação policial foi apresentado naquele dia na Delegacia de Repressão a Entorpecentes da Polícia Federal do Rio de Janeiro sob a seguinte descrição: “(...) grande quantidade de material esverdeado acondicionado em sacos plásticos e potes, bem como espalhados pela casa, aparentando ser maconha" (Inquérito Policial: p. 100, vol. 1).

Àquela altura, Careca havia acionado seus advogados. Ficara sabendo que a ação policial que o tirara naquela manhã de casa para leva-lo à delegacia, e depois ao cárcere, havia começado oito meses antes, a partir de escutas telefônicas autorizadas pela Justiça em uma investigação policial que não o tinha inicialmente como alvo. No documento em que a quebra de sigilo telefônico de pessoas que Careca sequer conhecia é solicitada, dando origem aos atos administrativos que o levariam à prisão meses depois, a justificativa era desbaratar uma quadrilha que realizava o tráfico de drogas na zona sul da cidade. Suposta organização criminosa apresentada como "grupo devidamente articulado e organizado, com o objetivo de efetuar reiterada prática de tráfico ilícito de entorpecentes no Estado do Rio de Janeiro" (Inquérito Policial: p. 2, vol. 1).

Como, então, Careca fora envolvido nesta trama? Ainda segundo o que pudemos apurar na leitura dos Inquéritos Policiais e na conversa com os advogados, Alemão, amigo pessoal de Careca, outro cultivador caseiro que fazia parte dos mercados clandestinos, diante de problemas com a colheita, comprou parte da produção de Careca a preço de grower pra grower visando realizar uma venda a preços de mercado, obtendo assim lucro considerável com a operação de atravessamento. Toda esta transação fora monitorada e gravada pelos grampos telefônicos da Polícia Federal, uma vez que, com o decorrer da investigação que se iniciara meses atrás, Alemão havia entrado no radar dos investigadores.

O monitoramento de um número crescente de pessoas investigadas levou a uma ação culminante que mobilizou grande número de agentes policiais para, segundo a verdade que se produz no âmbito do processo, desbaratar uma quadrilha especializada na venda de drogas na zona sul na cidade do Rio de Janeiro. Todos os celulares, computadores e outros aparelhos eletrônicos pertencentes aos incriminados também foram apreendidos, para posterior análise e produção de provas. O que é inequívoco afirmar a partir da leitura dos inquéritos policiais é que os policiais da Delegacia de Repressão a Entorpecentes da Polícia Federal no Rio de Janeiro, naquela ocasião, levaram para a delegacia e prenderam pessoas e plantas, principalmente muitas plantas.

Os advogados, acostumados a irem ao prédio da Polícia Federal por dever de ofício, na defesa de clientes, contam que nunca haviam visto a delegacia tão perfumada como naquele dia, resultado da presença ali de grande quantidade de pés de maconha, boa parte delas no estágio da floração, quando seu aroma é mais intenso. Enquanto isso, os depoimentos de testemunhas e acusados eram tomados. As testemunhas que figuraram no inquérito foram os policiais que participaram da operação. A condição dos cultivos caseiros no momento em que foram desestruturados pela ação policial é detalhadamente descrita nos autos do processo. Em relação ao que foi encontrado na casa de um do acusados temos a seguinte descrição, com cada detalhe sendo devidamente lembrado:

(...) uma estufa dentro de um quarto contendo 20 (vinte) vasos de plantas, conhecida como maconha. (...) a referida estufa foi muito bem elaborada, tinha sistema de refrigeração, lâmpada fluorescente tipo HPS com temporizador simulando dia e noite, lembrando que tal estufa encontrava-se em um quarto estufa, somente utilizado para isso (Inquérito Policial: p. 67, vol. 1).

Em outros casos, alguns elementos 
figuram como altamente incriminadores, gerando descrições como a seguinte: "resta claro que o plantio não era somente para consumo pessoal, reforça essa tese a presença da balança de pressão, apreendida no apartamento objeto da busca" (Inquérito Policial: p. 96, vol. 1). Em outro caso, os policiais, convertidos em testemunha, fazem ir para os registros a informação de que foram encontrados resíduos de maconha na balança. Até mesmo a presença de moedas estrangeiras de posse dos suspeitos pode contribuir para sua incriminação por via da produção do inquérito. Os policiais utilizam todos os sentidos nesta coleta seletiva de evidências para a produção se provas, até mesmo o olfato, em associações por vezes inusitadas.

(...) durante as buscas também foram encontrados valores em moeda estrangeira (dólar e euro), bem como reais. (...) tais moedas estavam impregnadas com forte odor de maconha, indicando sua utilização em prováveis movimentações de drogas (Inquérito Policial: p. 34, vol. I).

Os fatos são apresentados sob a ótica da polícia, dona da narrativa na armação do processo (KANT DE LIMA, 2019) cuja consequência prática pode ser a privação de liberdade de pessoas que caem nas malhas da Justiça. Contudo, a análise que nos propusemos fazer de processos públicos e oficiais de construção das verdades jurídicas a partir do viés policial, em complementaridade com nossa interlocução junto a advogados que acompanharam os casos atuando profissionalmente na defesa dessas pessoas que passaram à condição de réus, nos mostra que há muito mais elementos nas condutas humanas e sociais do que o filtro policiaresco pode ser capaz de explicitar. Ou, dito de outra maneira, do que é do seu interesse ressaltar.

\section{O filtro policial e judiciário}

O processo jurídico ao qual foram submetidos os acusados, tomado aqui como base para a construção da seção anterior, é produzido a partir de uma narrativa normativa e padronizada que tem como finalidade realizar a denúncia, punir e reprimir a conduta criminalizada a partir do ponto de vista das instituições policiais e de seus agentes. Como pode perceber o leitor, a própria narrativa aqui empregada para descrição e análise é impregnada - como não poderia deixar de ser - das lógicas e vocabulários de tais corporações. Trata-se de um procedimento inquisitorial (FOUCAULT, 2002; KANT DE LIMA, 2008) que leva em consideração os "fatos" seletivamente, a partir de pontos de vistas e intencionalidades para além do institucional, repousando em grande medida nas crenças e moralidades dos policiais que participaram da operação e realizaram as apreensões. Oito meses antes de Careca e Alemão serem presos, o processo para produção de provas contra os mesmos estava sendo aberto, onde escutas telefônicas serviam como principal fonte de investigação.

Os depoimentos dos agentes públicos são registrados no inquérito policial como testemunhas, sendo assim criados os fatos para compor e dar forma aos processos jurídicos que são decisivos na produção das incriminações, cujo efeito prático é o encarceramento de sujeitos por anos de suas vidas. A isto se arriscam perigosamente aqueles que, no Rio de Janeiro, se dedicam à jardinagem canábica com vistas a comercializar o produto. Sendo uma atitude já envolvendo alto risco de incriminação para aqueles que se dizem contra a comercialização do produto do cultivo, e até mesmo para aqueles que militam por formas mais liberais de regulação de tais condutas, torna-se ainda mais temerária para quem decide participar de tais mercados.

Uma das consequências disso é a dificuldade para a produção de uma etnografia sobre tal prática a partir de uma interlocução direta com os realizadores dos cultivos inequivocamente visando consumidores que o comprem. A solução por nós construída para superar esta dificuldade e realizar este estudo das relações sociais e econômicas engendradas a partir dos cultivos de canábis em escala caseira para fins comerciais no Rio de Janeiro trouxe também suas consequências (e seus acréscimos). Afinal, 
podemos discutir também aqui o funcionamento dos aparelhos jurídicos e policiais, em especial no que concerne, em parte, a repressão a práticas enquadradas como tráfico de drogas (Artigo 33 da Lei 11.343/2006). Gostaríamos de apresentar esta discussão, sem a pretensão de esgotá-las, na presente seção.

Foucault (2002) em "A verdade e as formas jurídicas" demonstra como as práticas sociais são compostas por domínios de saber que produzem novos objetos, conceitos, técnicas e principalmente novos sujeitos de conhecimento que detêm o poder na produção da verdade jurídica. São discursos e práticas que produzem verdades, que por sua vez podem produzir duras consequências nas vidas das pessoas, incluindo a privação de sua liberdade. Já no primeiro volume dos inquéritos de onde extraímos os elementos para nossa construção narrativa, observamos que o juiz da vara onde os processos são originados "MANDA" (escrito precisamente assim, com as letras maiúsculas) o delegado da Delegacia de Repressão a Entorpecentes (DRE) da Polícia federal "proceder a diligência ora ordenada, podendo, se necessário, efetuar arrombamento" (Inquérito Policial, p. 33, volume 1).

As práticas judiciárias - a maneira pela qual, entre os homens, se atribuem os danos e as responsabilidades, o modo pelo qual, na história do Ocidente, se concebeu e se definiu a maneira como os homens podiam ser julgados em função dos erros que haviam cometido, a maneira como se impõem a determinados indivíduos a reparação de alguma de suas ações e a punição de outras, todas essas regras, ou se quiserem, todas essas práticas regulares, é claro, mas também modificadas sem cessar através da história - me parecem uma das formas pelas quais nossa sociedade definiu tipos de subjetividade, formas de saber e, por conseguinte, relações entre o homem e a verdade que merecem ser estudadas (FOUCAULT, 1979, p. 8).

$\mathrm{O}$ inquérito policial que submeteu os cultivadores ao processo de incriminação, portanto, é a atualização de uma prática medieval de busca da verdade no interior da ordem jurídica.
Essa fórmula de investigação é encontrada nas práticas jurídicas, que são segundo Foucault, o modo pelo qual os membros das sociedades ocidentais podem ser julgados em função dos erros que cometem. Portanto, Foucault põe em análise os processos de formação de sistemas jurídicos em sociedades que se tornaram idealmente igualitárias, dando ensejo assim a formas processuais acusatoriais, sistemas que admitem "uma acusação, a qual é investigada publicamente, com a participação da defesa do acusado" (KANT DE LIMA, 2009, p. 46). Assim o fazendo, rejeitando a lógica de privilégios encarnada nos processos judiciais predominantes no Antigo Regime.

Já a atribuição de culpabilidades (mais do que responsabilidades) no Direito praticado no Brasil se estrutura a partir de lógicas bastante distintas, através de regimes inquisitoriais, oriundas da influencia das tradições romana e canônica. Consiste o modelo inquisitorial em uma forma de produção de verdades segundo a qual, após efetivada a denúncia (podendo ser, inclusive, anônima) "efetuam-se pesquisas sigilosas antes de qualquer acusação, não só para proteger a reputação de quem é acusado, mas também para proteger aquele que acusa de eventuais represálias de um poderoso acusado" (KANT DE LIMA, 2009, p. 46).

Pensamos não ser demasiado lembrar mais uma vez que, no início do século XIX, época na qual as outras nascentes nações da América, também de saída do julgo colonial, optaram pela via republicana, o Brasil foi o único país da região a iniciar a história de sua independência política em relação a Portugal em uma chave monárquica. Mais do que isso, o monarca brasileiro que proclamou a independência (Dom Pedro I), por ser filho legítimo e primeiro nome na linha sucessória de Dom João VI, monarca português, pertencia à mesma dinastia da monarquia dos tempos coloniais. Tal situação perdurou de 1822 a 1889. Além disso, o país foi o ultimo do chamado ocidente a abolir a instituição do modelo escravagista de produção por meio do tráfico negreiro oriundo de terras africanas. Tais características, evidentemente, marcam 
profundamente as instituições judiciárias brasileiras.

(...) O atual Código de Processo Penal, entretanto, apesar de afirmar que o processo é acusatorial, conformando-se, portanto, às disposições constitucionais, diz que tal processo pode ser precedido de um procedimento extrajudicial, conduzido pela autoridade policial, sob fiscalização do promotor e do juiz, de caráter inquisitorial (KANT DE LIMA, 2009, p. 46-47).

Por isso, em conformidade com a dogmática jurídica brasileira, a polícia pediu autorização à justiça para realizar escutas através de grampos telefônicos de pessoas acusadas de tráfico de drogas sem que os acusadores sejam apontados nos autos do processo. Sem que a origem da denúncia tivesse sido discriminada. Por isso, ainda, embora o enquadramento da conduta de Careca, de vender parte do excedente de sua produção caseira de maconha, seja inequivocamente efetuar o tráfico de drogas, não é, por outro lado, inequívoco, que fizesse parte de uma organização criminosa. Mas assim indica a acusação, feita com base no trabalho policial realizado inquisitorialmente no Brasil. Sobre a modalidade de grower pra grower de transações comerciais tendo como objeto de prover mercados e consumos de uma maconha de alta qualidade, embora impregnada de significações no meio nativo do cultivo caseiro carioca, o filtro policial e jurídico é absolutamente insensível para suas lógicas e valores.

A partir dos contatos acadêmicos e de pesquisa com pessoas que exercem a advocacia em articulação com a militância antiproibicionista, tivemos acesso a tais processos onde growers que cultivavam visando a comercialização do produto, respondem na justiça brasileira por tráfico de drogas. Dessas peças processuais interessa também extrair, não apenas a matéria prima para nossa narrativa, mas também, a partir de como os casos são registrados, alguns aspectos das ações policiais e judiciárias que produziram os processos de incriminação. Que cursos de ação nos casos de cultivos ilícitos aparentemente discretos podem levar a sua descoberta, denúncia formal, e consequentemente a tais processos de incriminação?

As estratégias metodológicas para a produção deste trabalho foram de feitio predominantemente qualitativo, com destaque para a leitura de peças processuais e a realização de entrevistas com roteiro semi-estruturado, visando assim, a partir desta dupla abordagem, embasar descrições de inspiração etnográfica sobre práticas e representações dos agentes incriminados (cultivadores), bem como também dos agentes incriminadores (policiais e membros do Judiciário). Desse modo, o objeto desta proposta de trabalho são os cultivos clandestinos de maconha - bem como a repressão correspondente a isto interposta pelas forças policiais - e sua contribuição, através de práticas comerciais, para a difusão do que se convencionou chamar, no Rio de Janeiro e em outros lugares do mundo, de "cultura canábica".

\section{Os Modelos de Tráfico de maconha: morro, asfalto, jardim.}

Ao mapear a discussão contemporânea em torno do tráfico de drogas nas ciências sociais, podemos encontrar diferentes pesquisas antropológicas e sociológicas que descrevem práticas mercantis onde produtos ilícitos são postos a venda. O foco deste trabalho, como já foi pontuado, é descrever práticas de comércio de maconha oriundas de cultivos domésticos, nos quais diferentemente do que geralmente ocorre com os outros modelos de "tráfico" que iremos apresentar aqui, a maconha cultivada em casa, se bem domesticada (VERÍSSIMO, 2016), resulta em flores de alta qualidade que são apreciadas por seu gosto, cheiro, textura e "onda", em mercados movimentados por apreciadores refinados (VELHO, 1998; VERÍSSIMO, 2017).

Por isso, a partir do material que pudemos consultar, os inquéritos policiais, procuramos descrever, dentro de tais limitações, a existência de redes de mercados de maconha em sua forma de flor e que funcionam independentemente das redes mais tradicionais do tráfico no Rio 
de Janeiro, predominantemente operadas por grupos criminosos associados a agentes do Estado, conhecido nas crônicas policiais cariocas como "o narcotráfico". Conhecido como "do green", "skunk", e outros codinomes, o produto de meses de cultivo e dedicação costuma ser vendido a preços nada baratos e em redes exclusivas quando comparados aos preços praticados e a publicidade das atividades que caracteriza as chamadas "bocas de fumo" . Na presente seção, buscando maior apuro na perspectiva analítica aqui proposta, pretendemos trazer a descrição, com base em trabalhos anteriores, feitos por outros autores, de duas formas conhecidas de se realizar o mercado ilícito de maconha no Rio de Janeiro.

Duas contribuições marcantes no campo dos estudos de mercados de drogas postas na ilicitude, e também sobre criminalidade e violência no Brasil, apresentam modalidades distintas de "tráfico" que tem como uma de suas principais substâncias a maconha prensada ${ }^{6}$. Michel Misse (1997) e Carolina Grillo (2008) são considerados pioneiros por descreverem a organização e as principais características das modalidades de comércio de maconha no morro e na pista, no Rio de Janeiro, respectivamente. A proposta de apresentar uma comparação por contraste entre o nosso objeto e os modelos descritos pelos autores consiste em trazer para o debate nas ciências sociais a análise de uma prática comercial que se diferencia justamente pela qualidade do produto, pelas formas de produção e transação final, que garantem um status diferenciado dentro da "cultura canábica" para o produtor/grower, para aquele que o transaciona, e também para o consumidor. São práticas completamente diferentes, mas que tomam formas jurídicas semelhantes durante o processo de produção da verdade legal nas malhas do direito penal (FOUCAULT, 1979).

Segundo o sociólogo Michel Misse (1997), o mercado ilegal e informal do Rio de Janeiro era dominado pela articulação entre agentes públicos (policiais, juízes, políticos etc.) e contraventores à frente do Jogo do Bicho, em um modelo que prevaleceu até o final de década de 1970. Apostas ilegais, transações imobiliárias fraudulentas e tráfico de maconha eram (e são) operados por redes que se intercomunicavam. Ainda segundo Misse, a popularização da cocaína durante a década de 1980 ganhou intensa visibilidade, pois foi diretamente associada, principalmente na crônica jornalística criminal, ao notável aumento da violência urbana. A diferença entre uma atividade econômica "formal" de outra "informal" é a sua maior ou menor subordinação à regulamentação estatal (MISSE,1997).

O caráter territorial-político-militar do comércio de drogas no Rio de Janeiro, que praticamente se confunde com os limites de centenas de comunidades urbanas pobres da cidade, transforma esse mercado ilícito e seus efeitos de violência em ponto de convergência, seja do sentimento público de insegurança, seja em foco privilegiado das políticas de criminalização (MISSE, 1997, p.3).

A descrição do sociólogo sobre a organização do tráfico de drogas no Rio de Janeiro explana o caráter fundamentalmente varejista, onde a mercadoria principal não é a maconha, e sim a cocaína, pois apresenta desde 1980, do ponto de vista dos mercadores, a melhor composição custo/benefício em relação às transações ilegais. Embora estes pontos de venda de produtos ilícitos cuja localização é conhecida por todos continuem sendo chamados de "bocas

5 Sobre esta modalidade de venda de maconha e outras drogas no Rio de Janeiro que são as "bocas de fumo", ver: MISSE, 2006.

6 Nas cidades do Sul e do Sudeste do Brasil, prevalece nesse mercado o chamado "prensado", canabis colhida em latifúndios paraguaios e colocada numa prensa para depois seguir na forma de pedra para os mercados brasileiro, argentino e uruguaio. Sendo assim, a maconha vendida ilegalmente no Rio de Janeiro, geralmente vinda do Paraguai, por motivos de transporte sob condição de ilegalidade, é submetida, na origem, ao processo de prensagem, sem os devidos cuidados na hora do cultivo e após a colheita. Por isso, quando comparadas ao "green", ao "skunk", não são considerados um produto de qualidade, embora os consumidores de maconha na forma do prensado também façam distinção entre "bons" e "maus" prensados. 
de fumo" (em alusão aos mercados de maconha tradicionais de antes do fim da década de 1970), a cocaína passou a crescer em importância, reconfigurando tais pontos de venda no varejo, que também passam a ser chamados por muitos consumidores e mercadores apenas de "boca", ou "movimento" (MISSE, 2006). Outra reconfiguração estrutural é o momento no qual, a partir de meados dos anos 1980, a maconha posta à venda no varejo, o "soltinho", que era proveniente do nordeste brasileiro, foi definitivamente substituído nos pontos de venda pelo produto oriundo do Paraguai, que passa a ser conhecido sob o nome de "prensado" (BARBOSA, 1998; VERISSIMO, 2017).

As drogas, nessa modalidade comercial que é o varejo praticado nas "bocas", são vendidas em unidades chamadas de "dolas", no caso da maconha, e "papéis", "sacos" ou "pinos" no caso da cocaína, sendo que o trabalho de acondicionar as unidades é chamado de "endolação". O preço das unidades depende da qualidade do produto e das condições de oferta, onde as relações com a polícia são um fator determinante para o valor final. A distribuição das drogas é descentralizada, portanto, nem sempre depende de contatos intermediários. Ou seja, um fornecedor de maconha, cocaína ou armas pode subir a favela, procurar o "movimento" e vender seu estoque. A origem das mercadorias também é diferenciada, podendo ser comprada na fronteira por caminhoneiros não-vinculados ao tráfico internacional, cargas que passam pelo circuito "Rio-São Paulo" com destino a outros países e drogas apreendidas pela polícia (MISSE,1997).

O comércio da maconha, segundo Misse (1997), com o passar do tempo, se tornou menos volumosos em recursos se comparado ao da cocaína nessa modalidade varejista de venda. Os responsáveis pelas transações específicas envolvendo maconha são chamados "gerente do preto" (assim como há o "gerente do branco", responsável pela cocaína), onde o status do gerente da maconha é inferior do que o do gerente da cocaína. O modelo apresentado por Misse (1997) consiste em uma estrutura que pode ser decomposta em três níveis: o "dono" e seus "gerentes" formam o primeiro nível da hierarquia; "os vendedores diretos" ("vapores" e "aviões") e "soldados" formam um segundo nível. E por último os "endoladores", uma parte dos "aviões" e os "fogueteiros" compõem o terceiro nível. Este modelo apresentado tem como característica principal as "ligações perigosas", termo cunhado para descrever conexões e contatos com a polícia através da negociação de "mercadorias políticas" de segurança e liberdade. É transacionando nesta modalidade de mercado que assim se configura (MISSE, 1997; VERISSIMO, 2015), marcadamente territorializado em favelas e periferias da cidade e sua região metropolitana, que um número muito significativo de consumidores de maconha encontra o produto para poder consumi-lo.

Outra modalidade de transações onde a maconha (também entre outras drogas) é um produto posto no mercado, que ocorre sobre bases sensivelmente diferentes das descritas por Michel Misse, é o chamado "tráfico da pista", tal como costuma ser nomeado no Rio de Janeiro. Descrito por Carolina Grillo em "Fazendo um doze na pista: um estudo de caso do tráfico de drogas na classe média" (2008), sua dissertação de mestrado pelo Programa de Sociologia e Antropologia da UFRJ, orientada por Misse. Esta pesquisa corresponde aos resultados de interlocuções realizadas no campo junto a mercadores de maconha e outras drogas cuja identidade social os associa com a chamada classe média das cidades do Rio de Janeiro e Niterói. As análises da antropóloga se dão sobre os discursos dos agentes com os quais foi possível conversar, buscando elucidar a dinâmica do mercado ilegal de drogas praticado por jovens tidos como de classe média, assim como compreender os sistemas de referências compartilhados pelos

7 A “mercadoria política” consiste em um bem público que é privatizado para fins individuais. A oferta e a demanda desses bens e serviços se distanciam do principio do mercado. A economia das "ligações perigosas" se alimenta das próprias políticas de criminalização que demarcam esses mercados. (MISSE, 1997). 
mesmos, o que corresponde a um estilo de vida.

O contraponto com as redes do tráfico operantes nas aglomerações de moradia de baixa renda permite conceber o chamado tráfico "da pista” ou "do asfalto" enquanto uma modalidade particular desse mercado, caracterizada por uma sociabilidade própria. São identificadas as formas de organização, hierarquia e implantação territorial em que a rede estudada funciona, apontando as circunstâncias sob as quais é possível a manutenção de uma "sociabilidade normalizada" em torno do comércio ilegal de drogas, caracterizada pelo o repúdio ao uso da violência na resolução dos conflitos. A descrição da circulação da confiança, dos interesses, do crédito e do prestígio completa o estudo de caso apresentado que trata de objeto ainda pouco explorado pelas ciências sociais, no Brasil (GRILLO, 2008, p.1).

Ou seja, diferentemente do que ocorre nos morros e favelas onde tradicionalmente se instalaram as "bocas de fumo", a quebra de contratos firmados verbalmente (uma vez que as transações, tanto no morro, quanto no asfalto, se dão na clandestinidade) não são resolvidas na base da violência. Ameaças de morte - bem como sua consequente efetivação - não fazem parte do repertório das relações sociais e econômicas aí vivenciadas.

A modalidade comercial de maconha na qual Carolina Grillo foca sua atenção é articulada em redes relacionais fundadas na amizade, sem que existam pontos de venda reconhecíveis e fixos, podendo circular através de encomendas telefônicas similar a uma espécie de delivery, que toma como marcador da distribuição a venda por peso, ou seja, um preço estabelecido a partir da unidade de medida grama. Este mercado é composto por empreendedores individuais que se associam, mas não compõem grupos formados à base do respeito e de uma hierarquia de obediência. Dessa forma, o "traficante" de classe média opera em grande vantagem com relação ao que se estabelece nas favelas da cidade. O estudo apresentado por Grillo (2008) toma como interlocutores jovens que transitam pelos diversos espaços simbólicos que compõe o "mundo jovem", portanto, quanto mais ecléticos forem seus "contatos", maior será o sucesso de suas práticas comerciais.

Com relação ás normais informais de segurança dessa modalidade de "tráfico" (BECKER, 2008), não se pode colocar um amigo em contato direto com um fornecedor sem antes o consultar e receber a permissão. Dessa maneira, o jovem interessado em ajudar os amigos que queiram adquirir maconha, não podendo oferecer o contato de seu fornecedor, deve ele mesmo comprar em maior quantidade e repassar aos interessados. Este é o mecanismo pelo qual se ampliam as redes sem expor os fornecedores, e também corresponde como o primeiro passo no envolvimento de um indivíduo nesta prática comercial. Muitas vezes o "jovem" inicia fazendo isso sem auferir para si lucro algum, mas, não raro, com o tempo e a frequência, pode passar a acontecer.

Essa passagem de usuário a vendedor não se dá por uma decisão interna que produz algum marco numa trajetória, mas por uma sequencia de empreendimentos descompromissados, através dos quais o jovem se encaminha para o tráfico, sem se dar conta da gravidade do processo (GRILLO, 2008, p.15).

Outro aspecto importante descrito pela antropóloga é o conceito de "sociabilidade normalizada", que corresponde a um contraponto em relação ao conceito proposto por Machado da Silva (1999) de "sociabilidade violenta". Machado (1999) compreende o mercado informal e ilegal de drogas situado nas favelas cariocas como violento (mesmo não sendo uma característica própria do tráfico de drogas), justamente devido à imprevisibilidade da negociação de mercadorias políticas em um meio onde em grande medida se naturaliza a conversão de uma linguagem (MISSE, 1997). Já Carolina Grillo (2008), como já foi observado, ao descrever o "tráfico da pista" observou que o emprego da força é condenado e evitado, mesmo nas situações de não pagamento de débitos e suspeitas de delação. O principal 
indicador de "sociabilidade normalizada" é a ausência de armas nas negociações, mas não somente. A ajuda recíproca e a confiança também são palavras fundamentais para a compreensão deste conceito, que também são características presentes e observadas em nosso estudo da modalidade comercial de maconha oriunda de cultivos domésticos.

Essas redes da pista são marcadas pela instabilidade dos fluxos comerciais, que geralmente são interrompidos por problemas de pagamento e flagrantes policiais que resultam em perda de mercadoria e prisão. Além disso, entre os agentes que formam os elos das redes de confiança e amizade por onde circula a maconha sendo transacionada, quando um dos deles decide deixar essa atividade, há uma quebra do equilíbrio entre demanda e oferta, que pode ocasionar tempos de relativa escassez do produto. Ao mesmo tempo, o grau de sucesso e fracasso depende das estratégias em evitar problemas com a lei. Sendo assim, o contexto descrito por Grillo (2008) possui diversos aspectos semelhantes à modalidade comercial que estamos colocando sob análise: o tráfico de maconha proveniente de cultivos domésticos.

Careca é cultivador de longa data e também é considerado por seus pares como membro da "cultura canábica". Utiliza a maconha de forma terapêutica, como foi descrito, e dentro de sua trajetória da vida decidiu vender seu excedente. De acordo com nossos interlocutores, os advogados, Careca foi seduzido por um "cafetão de grower pobre" que atualmente vive na Europa. "Quem transa é quem ganha a grana, e quem se arrisca é quem planta", nos dizem nossos interlocutores. Neste caso específico no qual o cultivador vende as flores cultivadas em sua própria casa, não é raro que repassem ao preço da mercadoria o risco de possuir plantas e ser enquadrado como "traficante" caso seja alvo de investigações policiais.

As categorias nativas "adiantar" e “fortalecer" são trabalhadas por Grillo (2008), e são descritas como atitudes de quem assimila a consciência do mercado e contribui para lubrificar os fluxos comerciais, estabelecendo relações de cooperação entre as partes envolvidas, ou seja, corresponde um auxílio entre os pares sem perder de vista a noção de reciprocidade. Adentramos neste assunto para explicar o que levaram Careca e outros envolvidos a serem presos. Careca vendeu para um conhecido alguns buds ${ }^{8}$ a preço de "grower para grower" para "adiantar" e "fortalecer" uma pessoa reconhecida no meio grower, como ele próprio. Este outro, ao adquirir as flores, não as consumiu. Ao invés disso, realizou um atravessamento para vender para outra pessoa. Foi onde depararam-se com um esquema de investigação que estava armado pela Polícia Federal visando desarticular uma "quadrilha".

Nota-se que o que mais chama a atenção da polícia neste caso não é circulação da maconha em si, mas sim o lucro gerado a partir destas transações. Nossos interlocutores, os advogados, ressaltaram que "o que chama a atenção é a grana”, portanto, a descrição deste caso é marcado também pela incriminação do lucro, ideologia antiga e de origem canônica (SALVANY, 1979), mas ainda marcante nos processos de doutrinação na formação jurídica no Brasil (KANT DE LIMA, 2009). Com base em nossas observações de campo, podemos afirmar que até mesmo entre os cultivadores que não comercializam o produto de suas práticas de jardinagem é grande o número daqueles que criticam aberta e entusiasticamente aqueles que vendem, precisamente porque lucram.

\section{Considerações Finais}

Entendemos como "cultura canábica" um conjunto de consumos, práticas e representações apropriadas em um vasto conjunto de padrões de interações entre humanos e não humanos, que incluem desde manifestações artísticas até potentes mercados (lícitos em alguns lugares do mundo, ilícitos em outros), tudo isso em torno de 
uma planta, a maconha, ou canábis ${ }^{9}$. Trata-se de planta proibida de existir no Brasil e em grande parte do mundo por conta de leis locais e tratados internacionais (LABATE; RODRIGUES, 2018).

Em nossos trabalhos anteriores, estabelecemos interlocuções, que embasaram nossas pesquisas, com cultivadores caseiros de maconha, masque,comojádissemos, sededicavam à jardinagem canábica visando exclusivamente a autossuficiência em relação a este produto, seja por motivos sociais (VERISSIMO: 2017), ou por motivos terapêuticos (MOTTA: 2020). Porém, ainda não tínhamos tido a oportunidade de colocar sob descrição da "cultura do cultivo" da maconha (VIDAL, 2010) sob a ótica daqueles que plantam maconha para vender o produto em um mercado bastante atraente a ponto de fazer com que muitos decidam se dedicar a tal prática, a despeito dos riscos de incriminação que ela implica.

Este assunto em torno do direito que tem ou deixa de ter o cultivador caseiro de maconha de auferir lucro do excedente produzido com suas práticas de jardinagens, justamente porque tais práticas produziram-se a partir da circulação de saberes entre pessoas que compartilham visões de mundo, filosofias e moralidades (SALVANY, 1949), torna-se polêmico entre aqueles que pretendem construir, no Rio de Janeiro, a "cultura canábica". Além disso, os cultivadores que plantam exclusivamente para uso social próprio e que repudiam a comercialização do produto do seu trabalho - os quais optamos por não tratar no presente trabalho - não raro, são acusados de tráfico, a despeito de não comercializarem nenhuma parte de sua produção (VERISSIMO, 2016; 2017). Muitas vezes tal repúdio é também uma estratégia de distanciamento e redução de riscos.

Não obstante, os cultivadores caseiros que vendem seu produto, ainda que por razões óbvias não entrem como tais nos ativismos em prol de formais mais liberais de regulação da circulação da maconha, participam, a seu modo, da produção e reprodução da assim compreendida "cultura canábica" no Rio de Janeiro. Afinal, como resultado de seu paciente, dedicado e amoroso trabalho junto às plantas leva novos perfumes e sabores (muitas vezes frutados) às praias, concertos musicais e estádios de futebol, que fumantes (e até mesmo não fumantes) reconhecem como sendo um produto distinto do prensado. Sendo assim, o mercado consumidor de seu produto produz um consumidor refinado, distinto do consumidor do morro e também de boa parte do da pista, capaz de reconhecer e muitas vezes popularizar alguns traços da "cultura canábica", propiciando assim sua relativa consolidação em escalas mais ampliadas.

Como nos disseram os advogados, o ativismo antiproibicionista, assim como aqueles que conscientemente se colocam como partícipes da "cultura canábica", se dividem entre aceitar ou não práticas comerciais envolvendo a maconha de origem caseira. Os círculos growers e os espaços frequentados, sejam virtuais ou presenciais, constituem lugares de interação e compartilhamento de saberes e técnicas que conectam atores a partir de suas experiências pessoais com o processo de domesticação da planta (VERÍSSIMO, 2017). O fato de Careca ter sido um membro ativo do Growroom o possibilitou ser respeitado pela sua eficiência e sucesso no meio grower, fato que estreitou laços de amizades inclusive com pessoas que condenavam o lucro da prática de cultivo de maconha.

Os advogados inclusive se consideram pessoas que mudaram a percepção com relação a este tema, que antes do acontecido condenavam tal prática, ehoje afirmam que este mercado (flores provindas de cultivos domésticos) inclusive colabora para a "redução de danos sociais", uma vez que não capitaliza o chamado "narcotráfico", mas também individuais, já que o produto comercializado é de alta qualidade. Portanto, segundo os advogados, quem cultiva para si está reduzindo os danos a partir de uma perspectiva individual e social, e quem comercializa está reduzindo os danos a partir de uma perspectiva

9 Do nome científico, Cannabis sativa L. 
social. Nota-se que este é um argumento utilizado inclusive para defender cultivadores domésticos de sistemas jurídicos inquisitoriais que tem como objetivo a condenação dos mesmos.

Como sabemos, o consumo de maconha, ou de qualquer substância de moderados ou acentuados efeitos sensoriais, não se restringe apenas a substância ou ao indivíduo que a consome. Ao mesmo tempo há um contexto relacional que atravessa o consumo das moléculas que formam a substância, que só é acessível pela experiência, não só de consumo, mas também do que se faz para obtê-la (ZIMBERG, 1984), ou seja, no presente caso, através do mercado e do cultivo de maconha. No Rio de Janeiro, associações simbólicas marcantes fazem com que muita gente prefira fumar maconha oriunda de cultivo caseiro (mesmo se dispondo a pagar mais caro), não só pela reconhecida melhor qualidade do produto, mas também porque assim o fazendo, deixa de estar contribuindo para a capitalização de grupos armados que realizam o mercado varejista do prensado.

E, vale destacar, que o intuito de descrever aqui tais práticas passa longe de ter um caráter de denúncia sobre qualquer forma de "ilegalidade", já que nossa proposta é estar além das visões e categorias que informam o direito, assim como também não cabe a este trabalho propor formas de resolver "problemas sociais". Remi Lenoir, em "Objeto Sociológico e Problema Social" (1998), propõe que a Sociologia se abstenha a dar soluções para conflitos sociais, se encarregando, portanto, de compreender tais conflitos a partir do exercício de relativização da própria moral e dos próprios valores.

Por tudo isso, esperamos ter assim contribuído para um debate sociológico de tais práticas estatais e sociais, tendo como fio condutor formas de socialização que estruturam usos e regulações (legais e ilegais) em torno da maconha. Desse modo, nossa proposta foi abordar antropologicamente processos de adesão a sistemas normativos e de crenças, a fim de embasar discussões sobre Políticas Públicas e Antropologia, considerando que o desenvolvimento de uma pesquisa coerente pode contribuir tanto para a disciplina antropológica quando para os debates no campo das políticas públicas (WEDEL \& FELDMAN, 2005).

\section{Referências Bibliográficas}

BARBOSA, Antônio Rafael. Um abraço para todos os amigos: algumas considerações sobre o tráfico de drogas no Rio de Janeiro. Niterói, EDUFF: 1998.

BECKER, H. Outsiders: estudos de sociologia do desvio. Rio de Janeiro, Zahar: 2008.

FOUCAULT, M. A verdade e as formas jurídicas. Rio de Janeiro, Pontifícia Universidade Católica do Rio de Janeiro: 1979.

GRILLO, Carolina. Fazendo doze na pista: um estudo de caso do mercado ilegal de drogas na classe média. Dissertação (Mestrado em antropologia) - Programa de Pós-Graduação em Sociologia e Antropologia, UFRJ, Rio de Janeiro, 2008.

KANT DE LIMA, Roberto. Ensaios de Antropologia e Direito. Rio de Janeiro, Editora Lúmen Júris: 2008.

. A Polícia na cidade do Rio de Janeiro: seus dilemas e paradoxos. Rio de Janeiro, Autografia: 2019.

LABATE, Beatriz; RODRIGUES, Thiago. (orgs). Políticas de drogas no Brasil: conflitos e alternativas. São Paulo, Mercado das Letras: 2018.

LENOIR, Remi. Objeto Sociológico e Problema Social. In:CHAMPAGNE, Patrick et al.. Iniciação à Prática Sociológica. Petrópolis, Vozes: 1998

MACHADO DA SILVA, L. A. Criminalidade violenta e ordem Pública: nota metodológica. Revista de Sociologia e Política, Curitiba, v.13, novembro, 1999, p.115-124.

MAUSS, Marcel. Ensaio sobre a Dádiva: forma e razão da troca nas sociedades arcaicas. In: 
MAUSS, Marcel. Sociologia e Antropologia. São Paulo, Cosac Naify: 2003.

MISSE, M. As ligações perigosas: mercado informal, ilegal, narcotráfico e violência no Rio. Contemporaneidade e Educação, Rio de Janeiro, v. 1, n. 2, 1997, p. 93-116.

Crime e Violência no Brasil contemporâneo: estudos de sociologia do crime e da violência urbana. Rio de Janeiro, Lúmen Júris: 2006.

MOTTA, Yuri. O paciente dedo-verde: uma etnografia sobre o cultivo e consumo de cannabis para fins terapêuticos na cidade do Rio de Janeiro. Rio de Janeiro, Autografia, 2020.

SALVANY, Flelix S. O Liberalismo é Pecado. São Paulo, Companhia Editora Panorama: 1949.

STUART MILL, John. O Utilitarismo. São Paulo, Editora Escala: 2007.

VELHO. Gilberto. Nobres e Anjos: um estudo de tóxicos e hierarquia. Rio de Janeiro, Editora Fundação Getúlio Vargas: 1998.

VERISSIMO, Marcos. As "bocas de fumo" e a cidade: notas para uma atualização do conhecimento sobre a regulação do comércio de maconha no Rio de Janeiro. In: XI Reunião de Antropologia do Mercosul, Montevidéu, 2015.

- Do maconheiro ao cannabier: os autocultivos domésticos e outras domesticações. In: MACRAE, Edward; ALVES, Wagner Coutinho. (orgs.). Fumo de Angola: canabis, racismo, resistência cultural e espiritualidade. Salvador, EDUFBA: 2016.

- Maconheiros, fumons e growers: um estudo comparativo do consumo e do cultivo caseiro de canábis no Rio de Janeiro e em Buenos Aires. Rio de Janeiro, Autografia: 2017. e a cultura do cultivo de maconha no Brasil. Monografia (Ciências Sociais) - Bacharelado em Ciências Sociais, UFBA, Salvador, 2010.

WEDEL, J; FELDMAN, G. Why na anthropology of public policy? At Anthropology today, Vol.21, No 1.2005

ZINBERG, N. Drug, set and setting: the basis for controlled intoxicante use. New haven, Yale University Press: 1984. 